\title{
Software Developer Selection: A Holistic Approach for an Eclectic Decision
}

\author{
Santanu Kr. Misra \\ Dept. of CSE \\ Sikkim Manipal Institute of Technology \\ (Manipal University) \\ Majitar, Rangpo \\ East Sikkim. India.
}

\author{
Amitava Ray \\ Dept. of Mechanical Engineering \\ Sikkim Manipal Institute of Technology \\ (Manipal University) \\ Majitar, Rangpo \\ East Sikkim. India.
}

\begin{abstract}
The problem for optimal team formation is an important issue for many software organizations especially for small and medium size organization because of the experience of employee, constraints and skill requirements for a particular project are neither is supported by database system nor it is possible for small and medium scale organization due to bit complex issue for them . More over success or failure of software product is mostly depends on the development team. Mostly people uses their managerial experience to form software development team, but always it cannot meet the optimal decision specially when time and cost are the main constraints and of employee pool is having mixed kind of expertise. For that scenario in this paper our aim was to develop a selection model combining analytical hierarchy process (AHP) and Bayesian network for choosing the efficient developers. Additionally, that it is also defining the optimum order among developers based on their capability and also quantities among selected developers based on sensitivity values. The proposed model is based on expert's judgments and the human error is inevitable. Therefore, the robust design of quality developer selection is to be investigated.
\end{abstract}

\section{General Terms}

Multi-criteria decision making.

\section{Keywords}

Developer selection, Analytic hierarchy process, Bayesian network model, scoring model, Sensitivity values.

\section{INTRODUCTION}

Successful software project management depends on two most important factors such as the appropriate planning of the project development and the estimation of appropriate resource allocation [1]. Human resource is also incurring same weightage as of physical and technical resources [3].In software organization perspective human resources play a critical role in software project success or failure. However, people continue with paying least interest for the human resource selection rather tends to focus more on the technical side. Non competent or defective people assignment leads to the main human factor-related issues affecting software project success. Sometimes leads to a problem for not fulfillment of delivery in stipulated time period [2]. Generally, people are assigned to roles and project teams are formed on the basis of project leaders' experience of for people selection. The experience of employee, constraints and skill requirements for a particular project are neither is supported by database system nor it is possible for small and medium scale organization as because of complexity. Here the number of combinations of possible role assignments for the available employees can be a problem with too large a solution space. This makes this stage practically impossible to tackle efficiently without the help of decision support systems based on mathematical models that represent the problem to be solved as objectively as possible. The analytical model proposed here combination of AHP model and Bayesian network model will help to determine the right judgment in developer selection for a particular software project based on project specific technical expertise.

Therefore, this analytical model considering both qualitative and quantitative factors for developer selection. The following sections are organized as follows: first we present the past research works done by the researchers in section 2 . Then nomenclatures and AHP method has been discussed in section $3 \& 4$ respectively. Section 5 discusses the background of the Bayesian model. The sensitivity analysis is discussed in section 6. The proposed methodology has been discussed in section 7. Validation of proposed model has been elaborated in section 8. Finally, and conclusion of the research have been highlighted in section 9 .

\section{LITERATURE SURVEY}

In the past literature regarding the assignment of software developers Acuña et al. emphasized on human capabilities in software development by stating that experience of manager, heuristic knowledge, instinct help manager to decide developers [1]. Tsai et al. [3], in his paper described the selection of resources using CRD method and Taguchi's parameter design approach. CRD methods focus on resource scheduling rather than the activity scheduling and selection of human resource. Taguchi's parameter design approach is based on dynamic and stochastic condition. That also not focused on selection method of efficient human resources for fulfillment and delivery of software project in timely manner to reduce the cost. In [8], the authors proposed the Grey decision model for selecting contractors, but the contractors may have uncertain, undefined, fuzzy and vague attributes which may lead complexity in the selection of contractors. In this scenario Grey model works satisfactorily but it does not meet the human resource selection with fixed criteria. Method like AHP discussed in various literature [9][24][26][27][28] as a multi criteria decision making approach may also be considered for selection of human resources. In [6], the author discussed about the AHP model to prioritize the substitution of human resource considering different organizational, client and application attributes. But did not focused on selection of 
human resource based on project specific efficiency. In [4], researchers proposed a LP assignment model to match resource to tasks when optimum skill set are not available, but did not focus on selection of human resource based on project specific efficiency. Paper [5], focused on flexibility of requirements specification using special format that expresses the required team capabilities using fuzzy descriptors. But they also did not focus for the selecting developers based on project specific skill set. In paper [35], researchers proposed a personnel selection system based on fuzzy AHP for dealing with both qualitative and quantitative criteria. A fuzzy multiple criteria decision making (MCDM) methodology based on the TOPSIS for selecting employee presented in [36]. In another study [37], focused on Analytic Hierarchy Process (AHP) and two sided matching based Decision Support System (DSS) for military personnel selection. In [38], a new approach in traditional fuzzy TOPSIS method for manager selection has been discussed. That is veto threshold which shows the minimum requirements of decision makers from each alternative on each criterion. A quantitative and systematical method of selecting virtual team members for open innovation is discussed in [39]. In [40], researchers proposefour-layered fuzzy expert system architecture for evaluating personnel capabilities with identified criteria. A methodology for competency based personnel selection using Computation with Words (CWW) accompany with specific architecture of Perceptual Computer (Per-C) and the Linguistic Weighted Average (LWA) for construction firms [41].

Therefore, the extensive literature survey reveals the following drawbacks of the existing methodology:

-The existing methodologies do not consider multi-talented professionals.

-Skills and performance evaluations are not considered.

-The robustness of the system has not been discussed in the existing model.

-In most of the cases, researchers focus on the flexibility rather optimality and the system does not give the optimal ranking.

The efficiency in producing the software lines of code (SLOC) has not explored by the researchers. Only [10] uses Software Line of Code (SLOC) in unit time as a utility function in Bayesian network model to achieve the rating of utility among several software developers. In this paper, we present a new analytical approach applied to the problem of software development team selection. Our model extends the previous work that uses Bayesian Network model for ranking of the alternatives [10]. The extensions of our approach target the following observations on existing models:

The proposed model for developer selection encounters all these above limitations and extends in several ways. The objective of the model is to select developers for team formation having maximum capacities of technical requirements and restricts on team size as constraints. In this model, integrated AHP and Bayesian Network propose the new direction for selecting efficient and talented developers considering both qualitative and quantitative aspects. The limitation of the model is that it does not consider the constraints like budget and project termination limits.

\section{NOMENCLATURE}

$\operatorname{DVLPj}=$ jth Developer, $\mathrm{j}=\{1,2,3,4, \ldots . .8\}$.

$\mathrm{CR}=$ Consistency Ratio.
$W_{i}=$ Weight Vector for decision criteria(s). $i=\{1,2,3\}$.

$R_{i j}=$ Rating values for decision criteria. $i=\{1,2,3\}$ and $j=$ $\{1,2,3,4 \ldots \ldots, 8\}$.

$\mathrm{U}(\mathrm{ak}, \mathrm{Hi})=$ Utility function.

$\mathrm{P}(\mathrm{H} \mid \mathrm{a})=$ Probability of $\mathrm{H}$ while ' $\mathrm{a}$ ' occurs.

DI $\mathrm{i}=$ Developer's Index. $\mathrm{i}=\{1,2,3, \ldots \ldots ., 8\}$.

\section{ANALYTICAL HIERARCHY PROCESS (AHP)}

The Analytical Hierarchy Process [9][24][26][27][28][29] is a powerful and flexible multi criteria decision making method that can be applicable in variety of decision making situation from simple to complex situation. It is specially used to quantify managerial judgment of the relative importance of each of several conflicting criteria used in decision making process. In this method a problem is put into a hierarchical structure as follows:

a) The overall objective of the decision.

b) Factors or criteria for the decision.

c) Sub factors under those factors.

d) Decision option.

The steps involved in AHP model are as follows:

Step-1: List the overall goal, criteria and decision alternatives.

Step-2: Develop a pair wise comparison matrix. Rate the relative importance between each pair of decision alternatives and this rate is based on Saaty's nine point scale (Table7). The matrix lists the alternatives horizontally and vertically and has the numerical rating comparing the horizontal (first) alternative with the vertical (second) alternative.

Step-3: Develop a normalized matrix by dividing each number in a column in the pair wise comparison matrix by its column sum.

Step-4: Develop a priority vector. Average each row of the normalized matrix. The row average forms the priority vector of alternative preferences with respect to the particular criterion.

Step-5: Calculate the Consistency Ratio [CR]. Calculate the eigenvector or the relative weights and for each matrix of order $n$. Compute consistency index using $\mathrm{CI}=\frac{\left(\beta_{\max }-\mathrm{n}\right)}{(\mathrm{n}-1)}, \mathrm{RI}=$ Random Inconsistency $=1.987(\mathrm{n}-2) / \mathrm{n}$ and $\mathrm{CR}=\mathrm{CI} / \mathrm{RI}$.The acceptable CR range varies according to the size of matrix. That is 0.05 for the 3 by 3 matrix, 0.08 for a 4 by 4 matrix and 0.1 for all larger matrices, $\mathrm{n}>=5$ [ 9][28].

Step-6: Develop the overall priority vector by multiplying normalized matrix of criteria with the priority matrix of decision alternatives which is formed with priority vectors of different criteria. With this priority values judgment is been taken care. Acceptable consistency value helps to ensure the decision maker reliability to determine the priorities for the set of criteria [9] [27].

\section{BAYESIAN NETWORK MODEL}

Bayesian network incurs very important role for decision making in many domains. The key benefit of the Bayesian networks is that they enable users to explicitly handle and measure the inevitable uncertainty that is pervasive in software engineering $[10][15][16][17]$. The Bayesian networks also allow us to obtain predictions with incomplete 
information, and hence provide a solution in cases where data are scarce [10]. The utility in the decision networks signifies level of preference associated with possible actions. Let $\mathrm{A}=$ $\{\mathrm{a} 1, \mathrm{a} 2, \ldots, \mathrm{an}\}$ be a set of mutually exclusive actions. $\mathrm{H}$ is the associated random variables. The expected utility is calculated by:

$E U(a)=\sum_{H} U(a, H) P(H \mid a)$

Where $\mathrm{U}(\mathrm{a}, \mathrm{H})$ is utility value for each configuration of action and associated random variable and $\mathrm{P}(\mathrm{H} \mid$ a) is the probability distribution of $\mathrm{H}$ knowing that action ' $\mathrm{a}$ ' occurs. The relation between random variables follows Bayes' rule:

$$
P(x \mid y)=\frac{[P(y \mid x) P(x)]}{P(Y)}
$$

\section{SENSITIVITY ANALYSIS}

A mathematical model [7][11][29][31][32][33] is presented to combine the priority rating obtained from AHP model to the utility values obtained in Bayesian Network model to get the breakeven point analysis of the proposed model.

$D I i=\alpha \times S F M i+(1-\alpha) \times O F M i$

Where $\quad$ OFMi $=\frac{1}{\left[O F U i \sum_{i=1}^{n}\left(\frac{1}{\text { OFUi }}\right)\right]}$

OFM is the Objective Factor Measure. OFU is the Objective Factor Utility. SFM is the Subjective Factor Measure. DI is the Developer Index. $\alpha$ is the objective factor decision weight, $\alpha \geq 0$ but $\alpha \leq 1$. $n$ is the number of developers. SFM values are the priority rating values from the AHP model for each developer and OFM values are the Bayesian utility values for each developer. Using equation number (3) Developer-Index can be calculated. The choice of $\alpha$ is an important issue for selection of $\alpha$ depends on the decision-maker's preference regarding the importance of objective and subjective factor measures. However, the selection procedure may delineate different sets of result for different values of $\alpha$ for the same decision criteria values. Thus, a sensitivity plot to analyze the effect of $\alpha$ in the developer selection problem is strongly recommended.

\section{PROPOSED MODEL}

The step wise approach for the current analytical model is as follows:

Step--A: Identify the goal and decision alternatives.

Step--B: Identify the decision criteria. Decision criteria are totally based on software project skill oriented.

Step--C: Weights are assigned to each criteria based on a five point scale to set importance among different decision criteria.

Step--D: Computation of priority ranking among the all decision alternatives using AHP method.

Step--E: Computation the value of utility function for every alternative using:

$U\left(a_{k}, H_{i}\right)=W_{i} \times R_{i, j}$

Where $\mathrm{a}_{\mathrm{k}}$ is the set of decision alternatives, $\mathrm{H}_{\mathrm{i}}$ is the set of decision criteria, $\mathrm{W}_{\mathrm{i}}$ is weight vectors of decision criteria $\mathrm{i}=\{1,2,3\}$ and $\mathrm{R}_{\mathrm{i}, \mathrm{j}}$ is rating values of decision criteria $\mathrm{i}=\{1,2$, $3\}$ and $\mathrm{j}=\{1,2,3,4 \ldots, 8\}$ shown in the Table 6 and Table1.

Step--F: Computation of expected utility for every individual alternative applying equation

$E U(a)=\sum_{H} U(a, H) P(H \mid a)$

Where $\mathrm{U}(\mathrm{a}, \mathrm{H})$ value is obtained from equation (1) and $\mathrm{P}(\mathrm{H} \mid \mathrm{a})$ is the probability distribution of $\mathrm{H}$ selecting alternative ' $a$ '.

Step--G: Combine priority values from AHP and the Bayesian utility values from Bayesian network through sensitivity analysis as subjective factor measure and objective factor measure to get the actual rating among alternatives. Flow diagram of proposed model is shown in Figure1.

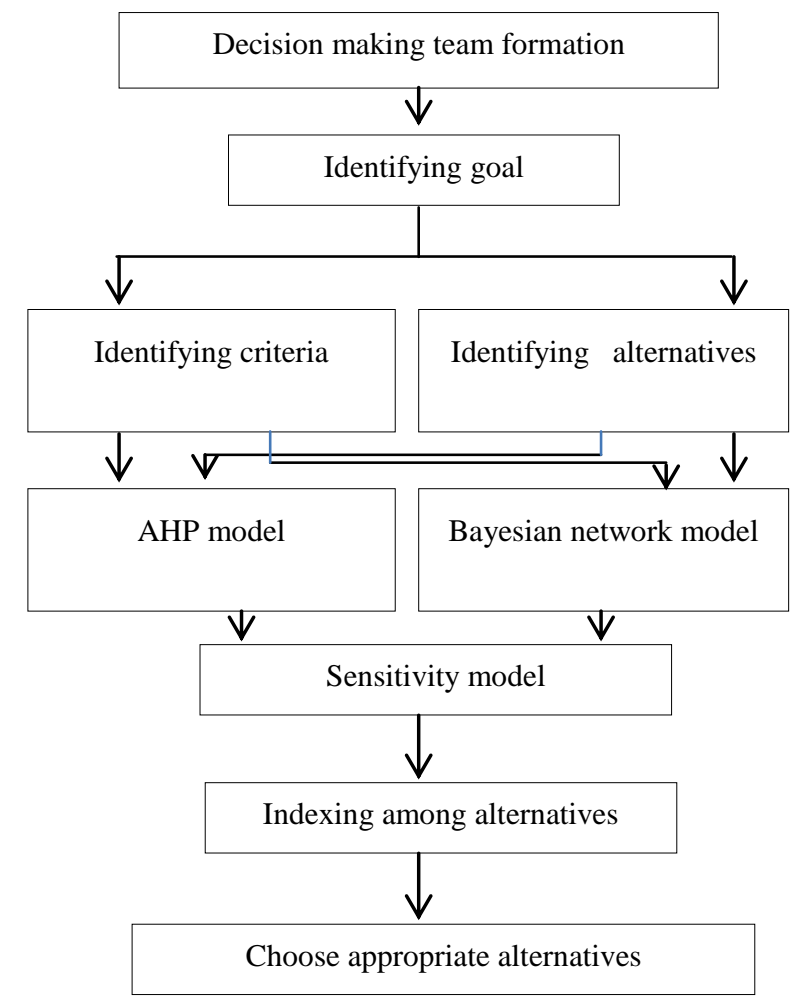

Figure 1: Flow diagram of proposed model

\section{VALIDATION OF PROPOSED MODEL}

Step--A: A software company wants to select the efficient software developers from the pool of eight developers. The company wants to select the five best developers.

Step--B: The identified decision criteria are 'Experience in software organization', 'knowledge of C' and 'knowledge of networking domain'. These criteria are based on project specific technical requirements.

Step--C: Ratings are assigned to the identified criteria based on five point rating shown in Table-1 below. 
Table 1: Criteria rating

\begin{tabular}{|l|c|c|}
\hline \multicolumn{1}{|c|}{ Criteria } & Rating Value & Meaning \\
\hline Experience & 4 & $\begin{array}{c}\text { Some what } \\
\text { important }\end{array}$ \\
\hline Knowledge of C & 5 & Very important \\
\hline $\begin{array}{l}\text { Knowledge of } \\
\text { networking domain }\end{array}$ & 5 & Very important \\
\hline
\end{tabular}

Rating values 1, 2, 3 are for very unimportant, somewhat unimportant, average important. Considering the technical requirements of the project the decision makers have assigned these numerical weightage to the corresponding criteria.

Step--D: The priority ranking among alternatives using AHP are calculated as:

Step-D01: Pair wise comparison matrix among all alternatives with respect to the criterion experience is calculated by Saaty's nine point scale. The result of the pair wise comparison among $\mathrm{n}$ alternatives is represented in a (n $\mathrm{x} n$ ) matrix. The matrix is shown in Table-2 below. The elements ofthe matrix area $_{i j}$ is either 1 if $i=j$; or is $\frac{1}{a_{i i}} \mathrm{if} i \neq$ jand $\mathrm{a}_{\mathrm{ij}} \neq 0$.

Table 2: Pair wise comparison matrix for criteria 'Experience'

\begin{tabular}{|c|c|c|c|c|c|c|c|c|}
\hline & $\begin{array}{c}\text { DV } \\
\text { LP1 }\end{array}$ & $\begin{array}{c}\text { DV } \\
\text { LP2 }\end{array}$ & $\begin{array}{c}\text { DV } \\
\text { LP3 }\end{array}$ & $\begin{array}{c}\text { DV } \\
\text { LP4 }\end{array}$ & $\begin{array}{c}\text { DV } \\
\text { LP5 }\end{array}$ & $\begin{array}{c}\text { DV } \\
\text { LP6 }\end{array}$ & $\begin{array}{c}\text { DV } \\
\text { LP7 }\end{array}$ & $\begin{array}{c}\text { DV } \\
\text { LP8 }\end{array}$ \\
\hline DV & 1 & 0.2 & 3 & 4 & 9 & 3 & 0.3 & 0.3 \\
LP1 & & 5 & & & & & 3 & 3 \\
\hline DV & 4 & 1 & 3 & 1 & 3 & 9 & 0.3 & 0.3 \\
LP2 & & & & & & & 3 & 3 \\
\hline DV & 0.3 & 0.3 & 1 & 0.3 & 3 & 0.2 & 0.1 & 0.1 \\
LP3 & 3 & 3 & & 3 & & 5 & 66 & 25 \\
\hline DV & 0.2 & 1 & 3 & 1 & 2 & 1 & 0.1 & 0.2 \\
LP4 & 5 & & & & & & 66 & 5 \\
\hline DV & 0.1 & 0.3 & 0.3 & 0.5 & 1 & 0.1 & 0.1 & 0.1 \\
LP5 & 1 & 3 & 3 & & & 66 & 25 & 66 \\
\hline DV & 0.3 & 0.1 & 4 & 1 & 6 & 1 & 0.1 & 0.1 \\
LP6 & 3 & 1 & & & & & 1 & 25 \\
\hline DV & 3 & 3 & 6 & 6 & 8 & 9 & 1 & 1 \\
LP7 & & & & & & & & \\
\hline DV & 3 & 3 & 8 & 4 & 6 & 8 & 1 & 1 \\
LP8 & & & & & & & & \\
\hline
\end{tabular}

The Consistency Ratio(CR) using mentioned equation in the step5 of section 4 , for the criterion experience is 0.1342 .

Step-D02: Pair wise comparison matrix among all alternatives with respect to the criterion 'Knowledge of C' are calculated in same way and shown in the Table-3 below.
Table 3: Pair wise comparison matrix for criteria 'Knowledge of $C$ '

\begin{tabular}{|c|c|c|c|c|c|c|c|c|}
\hline & $\begin{array}{c}\text { DV } \\
\text { LP1 }\end{array}$ & $\begin{array}{c}\text { DV } \\
\text { LP2 }\end{array}$ & $\begin{array}{c}\text { DV } \\
\text { LP3 }\end{array}$ & $\begin{array}{c}\text { DV } \\
\text { LP4 }\end{array}$ & $\begin{array}{c}\text { DV } \\
\text { LP5 }\end{array}$ & $\begin{array}{c}\text { DV } \\
\text { LP6 }\end{array}$ & $\begin{array}{c}\text { DV } \\
\text { LP7 }\end{array}$ & $\begin{array}{c}\text { DV } \\
\text { LP8 }\end{array}$ \\
\hline $\begin{array}{c}\text { DV } \\
\text { LP1 }\end{array}$ & 1 & 9 & 2 & 9 & 9 & 9 & 9 & 6 \\
\hline DV & 0.1 & 1 & 0.5 & 0.2 & 2 & 0.3 & 1 & 8.0 \\
LP2 & 1 & & & 5 & & 3 & & \\
\hline DV & 0.5 & 2.0 & 1 & 2.0 & 2.0 & 0.5 & 3 & 9.0 \\
LP3 & 0 & & & & & & & \\
\hline DV & 0.1 & 4 & 0.5 & 1 & 2 & 2 & 2 & 5 \\
LP4 & 1 & & & & & & & \\
\hline DV & 0.1 & 0.5 & 0.5 & 0.5 & 1 & 0.2 & 2 & 9 \\
LP5 & 1 & & & & & 5 & & \\
\hline DV & 0.1 & 3 & 2 & 0.5 & 4 & 1 & 3 & 4 \\
LP6 & 1 & & & & & & & \\
\hline DV & 0.1 & 1 & 0.3 & 0.5 & 0.5 & 0.3 & 1 & 1 \\
LP7 & 1 & & 3 & 0 & 0 & 3 & & \\
\hline DV & 0.1 & 0.1 & 0.1 & 0.2 & 0.1 & 0.2 & 1 & 1 \\
LP8 & 66 & 2 & 1 & & 1 & 5 & & \\
\hline
\end{tabular}

The Consistency Ratio(CR) for the criterion knowledge of C is 0.1910 (As per the mentioned equations in Step5 of section 4).

Step-D03: Pair wise comparison matrix for the criterion 'knowledge of networking domain is shown in Table-4 below.

Table 4: Pair wise comparison matrix for the criterion 'knowledge of networking domain'

\begin{tabular}{|c|c|c|c|c|c|c|c|c|}
\hline & $\begin{array}{c}\text { DV } \\
\text { LP1 }\end{array}$ & $\begin{array}{c}\text { DV } \\
\text { LP2 }\end{array}$ & $\begin{array}{c}\text { DV } \\
\text { LP3 }\end{array}$ & $\begin{array}{c}\text { DV } \\
\text { LP4 }\end{array}$ & $\begin{array}{c}\text { DV } \\
\text { LP5 }\end{array}$ & $\begin{array}{c}\text { DV } \\
\text { LP6 }\end{array}$ & $\begin{array}{c}\text { DV } \\
\text { LP7 }\end{array}$ & $\begin{array}{c}\text { DV } \\
\text { LP8 }\end{array}$ \\
\hline $\begin{array}{c}\text { DV } \\
\text { LP1 }\end{array}$ & 1 & 9 & 9 & 9 & 9 & 6 & 8 & 1 \\
\hline DV & 0.1 & 1 & 3 & 1 & 3 & 7 & 1 & 0.5 \\
LP2 & 1 & & & & & & & \\
\hline DV & 0.1 & 0.3 & 1 & 0.2 & 0.1 & 0.2 & 1 & 0.1 \\
LP3 & 1 & 3 & & & 1 & & & 2 \\
\hline DV & 0.1 & 1 & 5 & 1 & 0.2 & 1 & 0.2 & 0.1 \\
LP4 & 1 & & & & 5 & & & 6 \\
\hline $\begin{array}{c}\text { DV } \\
\text { LP5 }\end{array}$ & 0.1 & 0.3 & 9 & 4 & 1 & 1 & 1 & 0.1 \\
\hline DV & 0.1 & 0.1 & 5 & 1 & 1 & 1 & 0.1 & 0.1 \\
LP6 & 6 & 4 & & & & & 4 & 4 \\
\hline $\begin{array}{c}\text { DV } \\
\text { LP7 }\end{array}$ & 0.1 & 1 & 1 & 5 & 1 & 7 & 1 & 0.2 \\
\hline $\begin{array}{c}\text { DV } \\
\text { LP8 }\end{array}$ & 1 & 2 & 8 & 6 & 6 & 7 & 5 & 1 \\
\hline
\end{tabular}

The Consistency Ration (CR) for the criterion 'knowledge of networking domain' is 0.1978 .

Step-D04: The overall priority values among all the alternatives have calculated applying Step-6 mentioned in AHP section. It is shown in the Table-5. 
Table 5: Overall priority values

\begin{tabular}{|c|c|}
\hline Developers & Priority Values \\
\hline DVLP1 & 0.3849 \\
\hline DVLP2 & 0.0934 \\
\hline DVLP3 & 0.0529 \\
\hline DVLP4 & 0.0619 \\
\hline DVLP5 & 0.0663 \\
\hline DVLP6 & 0.0641 \\
\hline DVLP7 & 0.0289 \\
\hline DVLP8 & 0.1895 \\
\hline
\end{tabular}

These priority ranking introduces the subjective evaluation among the alternatives. On the other hand objective preference among the alternatives is calculated through the expected utility function of Bayesian model.

Step--E: In this connection computation of utility function are calculated by equation (3). To do these criteria weights for every alternative are considered from Table6. These weight values are assigned to the alternatives through technical interview in a nine point scale (Table7). Rating values are obtained from the Table1.

Table 6: Criteria wise weight values for alternatives

\begin{tabular}{|c|c|c|c|c|c|c|c|c|}
\hline Criteria & $\begin{array}{l}\text { D } \\
\text { V } \\
\text { L } \\
\text { P } \\
\mathbf{1}\end{array}$ & $\begin{array}{l}\text { D } \\
\text { V } \\
\text { L } \\
\text { P } \\
2\end{array}$ & $\begin{array}{l}\mathbf{D} \\
\mathbf{V} \\
\mathbf{L} \\
\mathbf{P} \\
\mathbf{3}\end{array}$ & $\begin{array}{l}\text { D } \\
\text { V } \\
\text { L } \\
\text { P } \\
4\end{array}$ & $\begin{array}{l}\text { D } \\
\text { V } \\
\text { L } \\
\text { P } \\
5\end{array}$ & $\begin{array}{l}\text { D } \\
\text { V } \\
\text { L } \\
\text { P } \\
6\end{array}$ & $\begin{array}{l}\text { D } \\
\text { V } \\
\text { L } \\
\text { P } \\
7\end{array}$ & $\begin{array}{l}\text { D } \\
\text { V } \\
\text { L } \\
\text { P } \\
8 \\
\end{array}$ \\
\hline Experience & 9 & 3 & 3 & 8 & 3 & 9 & 3 & 8 \\
\hline $\begin{array}{c}\text { Knowledge } \\
\text { of C }\end{array}$ & 2 & 7 & 2 & 5 & 5 & 3 & 8 & 8 \\
\hline $\begin{array}{c}\text { Knowledge } \\
\text { of Networking } \\
\text { domain }\end{array}$ & 3 & 4 & 8 & 3 & 5 & 5 & 8 & 2 \\
\hline
\end{tabular}

Step--F: Overall utility are calculated through the equation no. (4). Here $\mathrm{U}(\mathrm{a}, \mathrm{H})$ is obtained from equation no. (3) and, the probability distribution over criteria are calculated through the Bayes' theorem and shown in Table8. After that overall utility for all individuals are composed and shown in the same table. These overall utilities are considered as the objective factor measure.

Step--G: Once the subjective preference using AHP model and objective preference using Bayesian model for all alternatives have been identified, then by applying sensitivity analysis equation no. (2), actual indexing is made. These indexing are shown in the Figure2.
Table 7: Saaty's nine point scale

\begin{tabular}{|c|c|}
\hline $\begin{array}{c}\text { Compared to 2nd alternative, } \\
\text { the 1st alternative is }\end{array}$ & $\begin{array}{c}\text { Numerical } \\
\text { rating }\end{array}$ \\
\hline Extremely preferred & 9 \\
\hline Very strongly preferred & 7 \\
\hline Strongly preferred & 5 \\
\hline Moderately preferred & 3 \\
\hline Equally preferred & 1 \\
\hline $\begin{array}{c}\text { Intermediate judgment between } \\
\text { two adjacent judgment }\end{array}$ & $2,4,6,8$ \\
\hline
\end{tabular}

Table 8: Probability distribution over criteria

\begin{tabular}{|c|c|c|c|c|c|c|c|c|}
\hline & $\mathbf{D}$ & $\mathbf{D}$ & $\mathbf{D}$ & $\mathbf{D}$ & $\mathbf{D}$ & $\mathbf{D}$ & $\mathbf{D}$ & $\mathbf{D}$ \\
& $\mathbf{V}$ & $\mathbf{V}$ & $\mathbf{V}$ & $\mathbf{V}$ & $\mathbf{V}$ & $\mathbf{V}$ & $\mathbf{V}$ & $\mathbf{V}$ \\
& $\mathbf{L P}$ & $\mathbf{L P}$ & $\mathbf{L P}$ & $\mathbf{L P}$ & $\mathbf{L P}$ & $\mathbf{L P}$ & $\mathbf{L P}$ & $\mathbf{L P}$ \\
$\mathbf{1}$ & $\mathbf{2}$ & $\mathbf{3}$ & $\mathbf{4}$ & $\mathbf{5}$ & $\mathbf{6}$ & $\mathbf{7}$ & $\mathbf{8}$ \\
\hline Experience & 0.6 & 0.1 & 0.1 & 0.4 & 0.1 & 0.4 & 0.1 & 0.4 \\
& 1 & 7 & 8 & 6 & 9 & 8 & 2 & 0 \\
\hline $\begin{array}{c}\text { Knowledge } \\
\text { of C }\end{array}$ & 0.1 & 0.5 & 0.1 & 0.3 & 0.3 & 0.1 & 0.4 & 0.4 \\
Knowledge & 0.2 & 0.2 & 0.6 & 0.1 & 0.4 & 0.3 & 0.4 & 0.1 \\
of & 2 & 9 & 5 & 9 & 1 & 2 & 4 & 1 \\
$\begin{array}{c}\text { Networkin } \\
\text { g }\end{array}$ & & & & & & & & \\
\hline Overall & 26. & 26. & 29. & 26. & 13. & 27. & 35. & 32. \\
utility & 86 & 04 & 66 & 07 & 63 & 98 & 84 & 7 \\
\hline
\end{tabular}

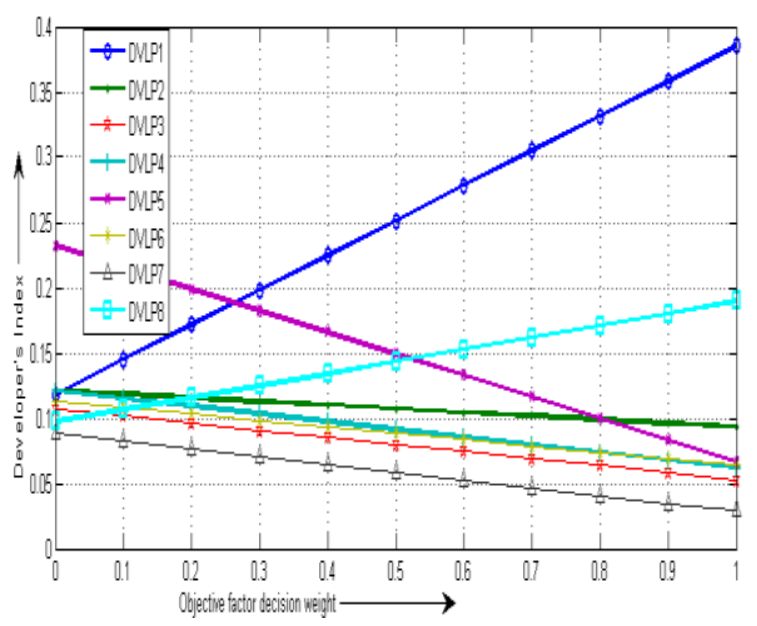

Figure 2: Sensitivity plot for indexing 


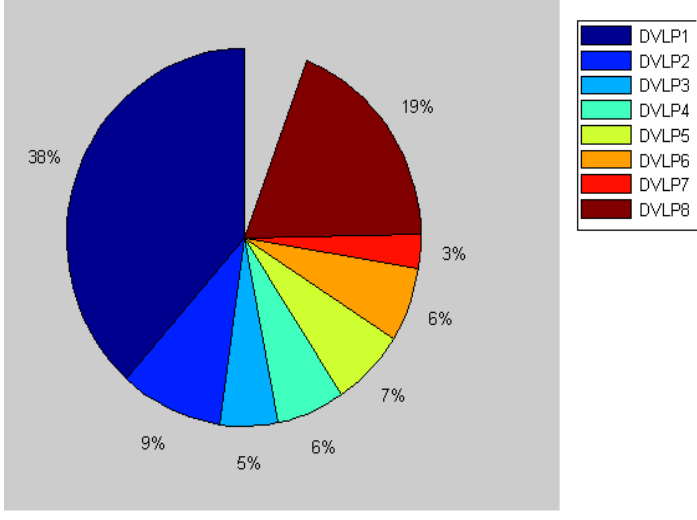

Fig3: Sensitivity plot

The figure 2 shows the indexing among the alternatives. From this graph it is clear that the ranking among the developers are like

\section{DVLP1 $>$ DVLP8 $>$ DVLP2 $>$ DVLP5 $>$ DVLP4 $>$ DVLP6 $>$ DVLP} $3>$ DVLP7. From this ranking the decision makers can easily identify the most suitable five developers. Figure 3 shows the pie chart representation of the result.

\section{CONCLUSION}

The proposed developer selection model makes over some shortage of previous models. In particular our model uses a hierarchical assessment with numeric data to get appropriate ranking among all the developers to choose the most deserving candidates for particular project. Though, multiple criteria are internally used to define the objective the proposed methodology described here has been analyzed and it indicates several advantages:

1) It is well suited for dealing appropriate ranking of developers based on project specific skill.

2) It is simple and straight forward.

3) It takes minimum time for calculation and ultimately for choosing candidate.

Some weakness of our proposed method might be:

1) It does not consider cost, time-limit.

2) It does not include the detailed segmentation of project activities which play important role for developer selection.

So there is scope for further research in the areas where cost, time-limit and other detailed project specific segmentation can come under consideration.

\section{REFERENCE}

[1] S. T Acuña, N. Juristo, "Assigning people to roles in software projects," Software-Practice and Experience, vol. 34, pp. $675-696,2004$.

[2] K. R Linberg,"Software developer perceptions about software project failure: a case study," The Journal of Systems and Software, vol. 49, pp. 177-192, 1999.

[3] H.,Tsai, H. Moskowitz H. Lee, "Human resource selection for software development projects using Taguchi's parameter design," European Journal of Operational Research, vol. 153, issue 1, pp. 167-180, 2003.
[4] L. D. Otero, G.Centeno , A. Ruiz-Torres, C.E.Otero, “A Systematic Approach for Resource Allocation in Software Projects," Computers and Industrial Engineering, vol. 56, pp. 1333 - 1339, 2009.

[5] D Strad, and N Guid, "A fuzzy-genetic decision support system for project team formation" Applied Soft Computing 10 (2010) 1178-1187.

[6] R.Ho-Leung, "Using Analytic Hierarchy Process (AHP) Method to Prioritise Human Resources in Substitution Problem," International Journal of the Computer, the Internet [7] Amitava Ray, BijanSarkar and SubirSanyal "The TOC- Based Algorithm for Solving Multiple Constraint Resources" IEEE Transactions on Engineering management, vol. 57, no. 2, May 2010.

[7] Wang Wei and Zhi Liu-Zhuang "Contractors Selection based on the Grey Decision Model" IEEE conference 2007.

[8] Norita Ahmad and. Laplante Phillip A "Software Project Management Tools: Making a Practical Decision Using AHP" Software Engineering Workshop SEW-30 (SEW'06), IEEE 2006

[9] Thitaree,Noothong and DarichaSutivong "Software Project Management Using Decision Networks" Sixth International Conference on Intelligent Systems Design and Applications IEEE 2006.

[10] Arijit,Bhattachariyya, Bijan,Sarkar, Sanat Kumar Mukherjee, , Integrating AHP and QFD for robot selection under requirement perspective, International Journal of Production Research, vol.43, no.17, pp. 36713685 (2005),

[11] O. Bayazit, (2006), Use of analytic network process in vendor selection decisions.Benchmarking: An International Journal 13 (5), 566-579.

[12] T. L. Saaty, The Analytic Hierarchy Process. McGrawHill, NY, 1980

[13] A. M Mustafa \& F. J Al-Bahar,. "Project Risk Assessment Using the Analytical Hierarchy Process," IEEE Transactions on Engineering Management, 38 (1): 46-52. 1991

[14] I ,Stamelos, L,Angelis, P Dimou, and E Sakellaris, "On the use of Bayesian belief networks for the prediction of software productivity", Information and Software Technology, vol. 45, no. 1, January 2003, pp. 51-60.

[15] C-F, Fan, and Y.-C Yu, "BBN-based Software Project Risk Management", Journal of Systems and Software, vol.73, no. 2, October 2004, pp. 193-203.

[16] W Watthayu, and Y Peng, "A Bayesian Network Based Framework for Multi-Criteria Decision Making", Proceeding of the 17th International Conference on Multiple CriteriaDecision Making, 2004.

[17] G.,Derringer, R., Suich, "Simultaneous Optimization of Several Response Variables," Journal of Quality Technology, vol. 12, pp.214-219, 1980.

[18] R. K., Roy, "Design of Experiments Using the Taguchi Approach,” John Wiley \& Sons, Inc., 2001.

[19] B.H Boon, and G Sierksma, Team formation: matching quality supply and quality demand, European Journal of Operational Research 127 (2) (2003) 277-292. 
[20] T.L Tseng, , C.C H.W Huang,. R.R Chu,.Gung, Novel approach to multi-functional project team formation, International Journal of Project Management 22 (2) (2004) 147-159.

[21] A. M. Beckers, ,\& M. Z Bsat,.). A DSS classification model for research in human resource information systems.Information Systems Management, 19(3), 4150. $(1995$

[22] R. W Saaty,..Decision making in complex environments. Pittsburgh: Creative Decisions Foundation. (2003)

[23] A. A., Salo, \& R. P. Hamalainen,.On the measurement of preferences in the analytic hierarchy process. Journal of Multi-Criteria Decision Analysis, 6, 309-319. (1997)

[24] M., Huemann, A., Keegan, J.R., Turner,. Human resource management in the project-oriented company: a review. International Journal of Project Management 25 (3), 315-323. 2007

[25] T.L., Saaty, How to make a decision: the analytic hierarchy process, European Journal of Operational Research, 48(1): 9-26. 1990,

[26] R.N Wabalickis, , Justification of FMS with the analytic hierarchy process, Journal of Manufacturing Systems, 7: 175-182. 1988

[27] M., Yurdakul, , AHP as a strategic decision-making tool to justify machine tool selection, Journal of Materials Processing Technology, 146(3): 365-376. 2004

[28] A,Ray, B Sarkar, and S Sanyal, "An integrated theoryof- constraints,” in Proc. IEEE IEEM, 2007, pp. 25-29.

[29] P Vasant, , R Natarajan, and , S Yacoob "Decision making using modified S-curve membership function in fuzzy linear problem," J. Inform.Commun. Technol., vol. 2, pp. 1-16, 2002.

[30] A Ray, , B Sarkar, and S Sanyal, "A holistic approach for production outsourcing," Strategic Outsourcing: Int. J., vol. 1, no. 2, pp. 142- 153, 2008.
[31] A Ray, B Sarkar, and S Sanyal, "Outsourcing decision under utopian environment," J. Appl. counting Res., vol. 9, no. 3, pp. 181-191, 2008 .

[32] A Ray, B Sarkar, and S Sanyal, "Improved TOC for outsourcing decision," Int. J. Management. Sci. and Eng. Management. vol. 3, no. 4, pp. 303-311,2008.

[33] Thomson Neubauer and Christian Stummer "Interactive Decision Support for Multiobjective COTs selection" Proceedings of the 40th Annual Hawaii International Conference on System Sciences HICSS'07).Management, vol. 9, issue 1,2001.

[34] Z.Gungor, G.Serhadlioglu, S.ErhanKesen, 2009.A fuzzy AHP approach to personnel selection problem. Journal of Applied Soft Computing 9 (2009) 641-646.

[35] P.V.Polychroniou, I.Giannikos, 2009. A fuzzy multi criteria decision-making methodology for selection of human resources in a Greek private bank. Career Development International 14 (4) (2009) 372-387.

[36] I.Korkmaz,H.Gokcen,T.Cetinyokus, 2008. An analytic hierarchy process and two sided matching based decision support system for military personnel assignment. Journal of Information Sciences 178 (2008) 2915-2927.

[37] A.Kelemenis, K.Ergazakis, D.Askounis, 2011. Support managers' selection using an extension of fuzzy TOPSIS Journal of Expert Systems with Applications 38 (2011) $2774-2782$

[38] Wi Hyeongon, Oh Seungjin, and JungMooyoung, 2011. Virtual organization for open innovation: Semantic web based inter-organizational team formation. Expert Systems with Applications 38 (2011) 8466-8476.

[39] Daniel Luis Otero and Carlos E Otero, 2012. A fuzzy expert system architecture for capability assessments in skill-based environments. Expert Systems with Applications 39 (2012) 654-662.

[40] SiamakSafarzadeganGilan, ,Mohammad Hassan Sebt , VahidShahhosseini, 2012. Computing with words for hierarchical competency based selection of personnel in construction companies. Applied Soft Computing 12 (2012) 860-87. 